\title{
EPIDEMIC GASTRO-ENTERITIS OF INFANTS IN ABERDEEN DURING 1947
}

\author{
BY \\ C. GILES, G. SANGSTER, and J. SMITH \\ (From the City Hospital, Aberdeen)
}

Gastro-enteritis in infants continues to attract much attention and numerous papers on this subject are published. The prevalence of this disease and the high mortality often associated with it make it most desirable that further investigations should be undertaken in order, if possible, to determine the etiological cause or causes and to devise methods of prevention and control. It will be sufficient here to mention a few of the more recent contributions to the study of the general epidemiology of the disease such as those by Payling Wright (1946) and Deeny and O'Brien (1946), and to the records of specific outbreaks by Ormiston (1941), Bloch (1941), Brown et al. (1945), Bray (1945), Gunn (1945), Gairdner (1945), and Giles and Sangster (1948).

\section{Infantile Mortality in Aberdeen}

Since infantile gastro-enteritis is not a notifiable disease the only basis for comparing the disease incidence during 1947 with that of previous years is provided by the infant mortality rate and the death rate due to diarrhoeal diseases in children under one year. A steady fall in the infant death rate has been apparent in Scotland generally since 1915, and in 1946 Aberdeen's infant mortality compared favourably with that of the rest of Scotland. Thus the infantile mortality rate was 140 in 1915 and 50 in 1946, while the deaths from diarrhoeal diseases dropped during the same period from 57 to 8.5 per 1,000 births; the year 1947, therefore, with its total infant mortality of 64 per 1,000 live births and a corresponding rise in the death rate due to diarrhoea marks a substantial increase which was due almost solely to the epidemic of gastro-enteritis.

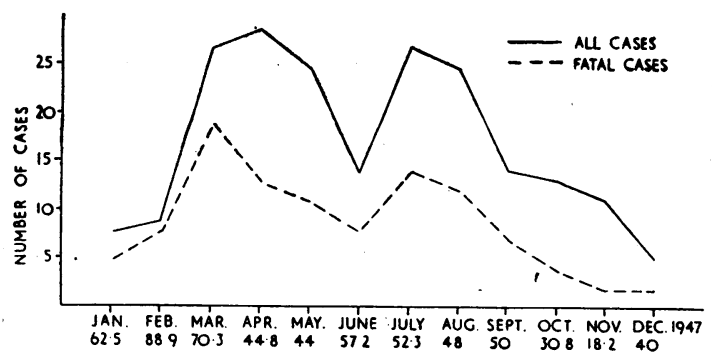

FIg. 1.-Seasonal incidence.

\section{Present Series}

Out of a total of 415 infants with diarrhoea who came under observation during the year, 207 were diagnosed as infective gastro-enteritis of uncertain etiology. Of these 207 cases, no less than 105 died, which amounts to an overall case fatality rate of 50.6 per cent., and eighty-three of the fatal cases belonged to the City while twenty-two had originally been transferred from the County to City Institutions. Out of eighty-three infants who were gravely ill at the onset, fifty-eight eventually died, giving a case fatality of $69 \cdot 9$ per cent.; a further 104 infants were moderately ill on admission and forty-seven or $45 \cdot 2$ per cent. died; the remaining twenty cases were mild and all recovered.

\section{Age-Sex Incidence}

The maximum incidence was associated with the first trimester with a peak at the second month and, in fact, fully a third of the cases were under two months, and 87 per cent. of the babies affected were within the first seven months of life. After seven months the figures decline sharply and only nine were more than one year old. On the whole the fatality rate appeared to be fairly constant for each monthly age-group in the first year of life. As regards sex, males were affected more frequently than females, although the mortality rate was practically the same in both (table 1).

\section{Seasonal Incidence}

The months with the greatest incidence of cases were March and April, with a further sharp rise in July (fig. 1), while the quarterly incidence of the disease was: first quarter forty-four cases, second quarter sixty-seven, third quarter sixty-five, and

TABLE 1 SEX INCIDENCE OF CASES

\begin{tabular}{l|c|c|c}
\hline & $\begin{array}{c}\text { Total } \\
\text { cases }\end{array}$ & $\begin{array}{c}\text { No. of fatal } \\
\text { cases }\end{array}$ & $\begin{array}{c}\text { Case } \\
\text { fatality }\end{array}$ \\
\hline Males & 114 & 56 & $49 \cdot 2$ \\
93 & 49 & $52 \cdot 7$ \\
\hline & 207 & 105 & $50 \cdot 6$ \\
\hline
\end{tabular}


fourth quarter twenty-nine. The peak incidence of gastro-enteritis used to occur during the third quarter of the year when the atmospheric and ground temperatures had risen above a certain minimum. In this connexion it is interesting to observe that the two periods with a peak incidence coincided with the coldest March $\left(6 \cdot 1^{\circ} \mathrm{F}\right.$. lower than the mean monthly average) and the hottest July $\left(2 \cdot 7^{\circ} \mathrm{F}\right.$. above the mean monthly average) recorded in Aberdeen during the last fifty years; therefore the incidence of gastro-enteritis does not appear to be confined to the hot seasons. The mortality was highest in February, and the unusually cold spell at that time may have been a contributing factor since chest complications were more common during that month and these always rendered the outlook more precarious. However, it will be seen from fig. 2 that the nosocomial infections outnumbered the external infections in the first four months of the year, and were largely responsible for the first peak in the incidence.

\section{Hospital and Institutional Infection}

There can be little doubt of the infective nature of gastro-enteritis, although the original source of infection often remains obscure, and the actual mode of spread can only be conjectured since the causative agent has not been specifically determined. In the present series 122 cases, or 58.9 per cent., were believed to have contracted their infection in hospital wards or institutions. Not infrequently patients were admitted to the various hospitals with a diagnosis of gastro-enteritis when there was no indication of a gastro-intestinal disturbance of any kind or merely a mild diarrhoea which responded to suitable dietetic treatment. After a period of five to ten days in hospital, cases of this type would suddenly develop the clinical signs and symptoms of severe gastro-enteritis.

The first ward outbreak, involving four cases, occurred towards the end of February, and three weeks later another group of eight cases appeared in the same ward, four of them simultaneously. The ward was used for the treatment of respiratory infections in children and babies, and at the time of the second outbreak twelve patients under the age of two years were being treated and thus the disease affected 66.6 per cent. of susceptible subjects, and further, all but one of the affected cases died.

Another outbreak which it was possible to study in some detail took place in another ward of the same hospital. This outbreak involved seven cases, four of which proved fatal. The first case had previously been transferred to the cubicle isolation ward for suspected gastro-enteritis and after a week's observation was transferred back for treatment of his original chest infection. Thirteen days later he developed true gastro-enteritis and died. In the other six cases, the first symptoms appeared within a fortnight of the re-admission of the first case to the ward and three died.
Four other distinct outbreaks were observed, two of these occurred in a second hospital, the third in another, and the fourth in a nursery. Two outbreaks in the medical and surgical wards of a children's hospital involved seventeen cases, fourteen of whom died. An outbreak of neonatal infection affected fourteen infants and nine died, while in the infants' nursery in which children with unsatisfactory home conditions were cared for, eight cases contracted infection and six died.

As a result of the first two outbreaks in hospital No. 1, it was decided to admit all infants with a doubtful history or symptomatology to a cubicle isolation ward set aside for the purpose. This procedure seemed to limit the extent of hospital infection but even in the cubicle ward there appeared to be some evidence of cross infection. It was never possible to establish how the infection was carried from one patient to another, though a

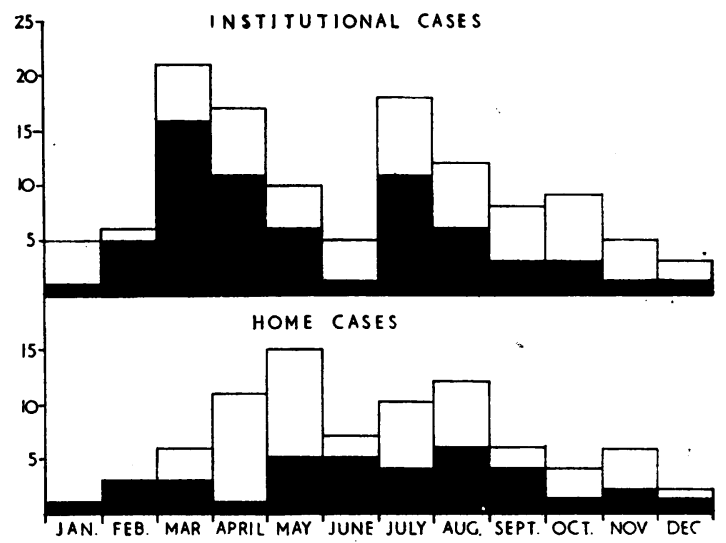

Fig. 2.--Institutional and non-institutional cases: total cases and deaths for each month.

breakdown in nursing technique through shortage of staff, particularly at night, seems to be the most probable explanation.

Fig. 2 shows the institutional and hospital infections in parallel with those cases who were thought to have contracted the disease at home. It is obvious that to prevent epidemics of gastroenteritis in hospitals and institutions for the care of infants the wards must be reconstructed and staffed in such a way as to limit the spread of infection. Cubicle isolation wards with complete sterilizing equipment and a nursing staff sufficient in number to maintain a complete eight-hour shift, and with specified duties, should be the aim in the administration of such hospitals.

\section{Incidence and Distribution of Outside Infections}

The highest incidence of cases occurring outside institutions was in April (eleven cases), May (fifteen cases), and August (eleven cases), and the 
TABLE 2

COURSE OF GASTRO-ENTERITIS IN 207 CASES

\begin{tabular}{|c|c|c|c|c|c|}
\hline \multirow[t]{2}{*}{ Acutely ill at onset } & $\begin{array}{l}\text { Death within } 72 \text { hours } \\
\text { Steady deterioration ar } \\
\text { Initial improvement an } \\
\text { Ensuing marasmus } \\
\text { Uneventful recovery }\end{array}$ & $\begin{array}{l}\text { and death } \\
\text { nd sudden } \\
\begin{array}{l}\ldots \\
\ldots\end{array}\end{array}$ & $\begin{array}{l}\cdots \\
\text { lapses } \\
\ldots \\
\ldots\end{array}$ & $\left.\begin{array}{l}\cdots \\
\cdots \\
\cdots\end{array}\right\} \begin{array}{l}\text { Death } \\
\text { Recovery } \\
\text { Death } \\
\text { Slow recovery }\end{array}$ & $\begin{array}{r}14 \\
17 \\
22 \\
14 \\
5 \\
5 \\
6\end{array}$ \\
\hline & Total $\ldots$ & $\cdots$ & $\cdots$ & $\cdots$ & 83 \\
\hline \multirow[t]{2}{*}{ Moderately ill at onset } & $\begin{array}{l}\text { Steady deterioration at } \\
\text { Initial improvement an } \\
\text { Ensuing marasmus } \\
\text { Uneventful recovery }\end{array}$ & $\begin{array}{l}\text { and death } \\
\text { nd relapse } \\
\ldots \\
\ldots\end{array}$ & $\begin{array}{l}\cdots \\
\cdots \\
\cdots \\
\cdots\end{array}$ & $\left.\begin{array}{l}\cdots \\
\cdots \\
\cdots\end{array}\right\} \begin{array}{l}\text { Death } \\
\text { Slow recovery } \\
\text { Death } \\
\text { Slow recovery }\end{array}$ & $\begin{array}{r}16 \\
27 \\
27 \\
4 \\
9 \\
21\end{array}$ \\
\hline & Total $\ldots$ & $\cdots$ & $\cdots$ & $\cdots$ & 104 \\
\hline \multirow[t]{2}{*}{ Mild at onset } & $\begin{array}{l}\text { Relapse and recovery } \\
\text { Uneventful recovery }\end{array}$ & $\begin{array}{l}\cdots \\
\cdots\end{array}$ & $\begin{array}{l}\cdots \\
\ldots\end{array}$ & $\begin{array}{l}. \\
\ldots\end{array}$ & $\begin{array}{r}2 \\
18\end{array}$ \\
\hline & Total .. & . & . & . & 20 \\
\hline
\end{tabular}

case mortality amongst patients who contracted their infection at home was 44.4 per cent. as compared with 58.9 per cent. in the institutional cases. A higher death rate among hospital infected cases might, however, be expected since the effects of gastro-enteritis were bound to be more severe in those who were suffering from, or had just recovered from another disease. Seventy out of the total of eighty-one home-infected cases came from the City of Aberdeen, and the remaining eleven from other burghs and County districts in the north-east of Scotland. The majority of cases were apparently unrelated, although the series included five sets of twins, and in ten more cases contact with a previously infected case could be established. The seventy City cases, with four exceptions, all came from crowded and mostly slum areas and a temporary hutted encampment in which eleven cases occurred, with nine fatalities.

\section{Predisposing Factors}

That artificial feeding is one of the most important predisposing factors in the causation of gastroenteritis has been known for a long time. In the present series only four infants, or 1.9 per cent., had been entirely breast-fed. In the remaining 203 patients, breast-feeding had been replaced or supplemented by the bottle for at least a week before the onset of symptoms. Another predisposing factor encountered in the present investigation, and already well recognized, was debility from defective nutrition or previous disease; sixty-three cases, or 30.5 per cent., had an infection before contracting gastroenteritis.

\section{Clinical Findings}

There is little point in again giving a detailed account of the clinical findings, as they do not

TABLE 3

RELATION OF ONSET TO DURATION AND END RESULTS OF ILLNESS

\begin{tabular}{|c|c|c|c|c|c|c|c|c|}
\hline \multirow{2}{*}{$\begin{array}{l}\text { Length of } \\
\text { illness in } \\
\text { weeks }\end{array}$} & & \multicolumn{3}{|c|}{ Acute' onset } & \multicolumn{3}{|c|}{ Insidious onset } & \multirow{2}{*}{$\frac{\text { Combined }}{\text { Total }}$} \\
\hline & & Recovered & Died & Total & Recovered & Died & Total & \\
\hline \multirow[t]{2}{*}{$\begin{array}{l}0-1 \\
1-2 \\
2-3 \\
3-4 \\
4-5 \\
5-6 \\
\text { Over } 6\end{array}$} & $\begin{array}{l}\cdots \\
\cdots \\
. \\
\cdots \\
\cdots\end{array}$ & $\begin{array}{r}2 \\
19 \\
25 \\
12 \\
9 \\
3 \\
-\end{array}$ & $\begin{array}{r}13 \\
26 \\
11 \\
5 \\
5 \\
1 \\
1\end{array}$ & $\begin{array}{r}15 \\
45 \\
36 \\
17 \\
14 \\
4 \\
1\end{array}$ & $\begin{array}{r}3 \\
12 \\
3 \\
3 \\
2 \\
- \\
1\end{array}$ & $\begin{array}{l}1 \\
4 \\
4 \\
6 \\
3 \\
1 \\
-\end{array}$ & $\begin{array}{r}4 \\
16 \\
7 \\
9 \\
5 \\
1 \\
1\end{array}$ & $\begin{array}{r}19 \\
61 \\
43 \\
26 . \\
19 \\
5 \\
2\end{array}$ \\
\hline & & & & 132 & & & 43 & 175 \\
\hline
\end{tabular}


appear to have differed substantially from those which have already been described.

The incubation period has often been very difficult to determine with certainty, both in cases which contracted their infection outside and inside institutions. This is probably due to the fact that it is often very difficult to determine when a particular infant started to develop the disease ; also it is impossible at the moment to determine the length of infectivity of a particular case. At best it can at present be concluded that the incubation period of the disease may be as long as thirteen days, is probably never less than two days, and may be commonly two to ten days.

The progress of the course of the illness in the 207 cases which came under observation is given in table 2. Apart from the high number of deaths, 105 out of 207 , the other marked feature is the relapse rate. Ninety of the cases showed evidence of relapse, and of these forty-seven died. This occurrence raises the question as to the possibility of more than one type of agent being responsible for the disease, and to the possibility that in the course of nursing these cases a cross infection occurs. On the other hand the relapse may be a normal consequence in the course of the illness.

During the whole year 180 cases came under direct observation in the City Hospital and an analysis of the initial symptoms showed the following incidence:

\begin{tabular}{|c|c|}
\hline Onset sudden & 132 \\
\hline " insidious & 43 \\
\hline ", uncertain & 5 \\
\hline Pyrexia & variable \\
\hline Vomiting & 109 \\
\hline Abnormal stools & 43 \\
\hline Vomiting and abnormal stools & 28 \\
\hline Anorexia & 18 \\
\hline Convulsions & 3 \\
\hline Dehydration-mild & 128 \\
\hline
\end{tabular}

The relation of the type of onset to the duration and end result of the illness is given in table 3 . From this it will be seen that after the exclusion of five cases in which the type of onset was uncertain, approximately 70 per cent. of cases terminated within three weeks. With regard to more protracted cases, there was occasional difficulty in determining exactly the cessation of the active phase since in many cases the stools were persistently abnormal and weights tended to fluctuate, although appetite was good and fairly normal feeds were tolerated. The average duration of all cases (180) was $17 \cdot 1$ days; for the fatal cases 15.7 days; for survivors $19 \cdot 5$ days. Three cases which might be described as fulminating died within thirty to forty-eight hours of the onset, and one case continued as long as sixty days. The presence of parenteral infection as a contributory cause of the disease has been studied by many workers and considerable controversy has arisen as to whether such an occurrence is part of the disease or simply a complication. In the series of 180 cases which have been under observation in hospital during the year, parenteral chest infections were prominent in thirty-nine cases, and a further eleven showed pulmonary involvement at a later stage. The question of inflammatory changes in the middle ear have been specially studied, but only in eight cases has evidence of middle-ear disease been obtained, and recognizable mastoiditis was not encountered.

\section{Pathological Findings}

In all a series of fifty-five autopsies was carried out over the year, an increase of thirty-one as compared to the series already reported (Giles and Sangster, 1948). These additional autopsies did not add materially to the knowledge which had already been obtained, and accordingly only a brief summary of the results need be given. A certain number of cases which died outside the City Hospital have been included in the series.

Respiratory tract. The upper respiratory tract showed no changes of any note. True pneumonic consolidation was found in fourteen out of fifty-five cases, while a further fifteen showed some basal congestion. In most instances the pneumonia or bronchopneumonia appeared to be a terminal event.

Cardiovascular system. In forty-five postmortem examinations the heart and blood vessels were normal; six cases exhibited pallor of the myocardium although microscopic examination failed to show any significant change; fatty degeneration was observed in one, and myocarditis with small foci of necrosis and round-cell infiltration in another. Two patients had been diagnosed as suffering from congenital heart disease, and at autopsy one was found to have a patent foramen ovale and the other a patent inter-ventricular septum.

Alimentary tract. An infant who has suffered from a profound gastro-intestinal disturbance for days and even weeks might be expected to show wellmarked changes in the stomach and intestine. It is, however, remarkable how often the gastrointestinal tract was devoid of any definite pathological change, either macroscopically or on histological examination. In the cases under discussion the oesophagus was invariably normal. The stomach was dilated in seven cases, all of which had received gastric drips before death. In eleven instances sub-mucous haemorrhages were present, a further nine merely showed congestion and oedema of the mucous membrane, while in thirtyfive no abnormality could be found. The postmortem appearances in the intestine varied, and in the more fulminating cases the appearances were more marked than in those with a more prolonged illness. The small intestine was normal in fourteen cases; on thirteen occasions sub-mucous haemorrhages were. encountered with marked mucosal congestion, whereas the remaining twenty-eight exhibited only mild hyperaemia, chiefly of the lower half of the ileum. True ulceration of the intestine 
was observed in only four cases. The large bowel was less frequently involved than the ileum, since in twenty-one out of fifty-five necropsies no nakedeye or histological lesions could be detected. A further twenty-four showed mild congestion, while only ten cases were characterized by haemorrhages and ulceration.

Abdominal viscera. The liver was the only organ which consistently showed some evidence of damage. This varied from slight fatty degeneration to generalized fatty changes and necrosis with little healthy liver parenchyma remaining. On eight occasions there was no fatty degeneration but the liver sinusoids were engorged while the remaining forty-six showed some degree of fatty change. In twenty of the latter the fatty degeneration was advanced, involving the whole lobule. Liver damage in itself does little to elucidate the etiology of gastro-enteritis for-it is frequently seen in infants who have died from other causes. Nevertheless, it is reasonable to suppose that the degree of liver damage is one of the most important prognostic factors. In view of the peripheral distribution of earlier fatty lesions it seems probable that the cause of- these changes might be sought for in portal toxaemia.

The spleen was found to be normal in thirty-six and congested in the remaining nineteen autopsies. The evidence of renal damage, though less spectacular than that of the liver, was nevertheless observed in a large proportion of cases. On seventeen occasions a variable degree of tubular degeneration was present, consisting of cloudy swelling of the convoluted and fatty degeneration of the collecting tubules. Four cases exhibited interstitial infiltration with small round cells and small medullary haemorrhages. Nineteen cases showed passive congestion of the kidney only, and in the remaining fourteen no abnormalities whatsoever were observed.

Lymphatic system and endocrine glands. The mesenteric nodes were often swollen and congested. In twelve specimens examined histologically five showed polymorphonuclear infiltration and oedema, while the remaining seven were congested. In three cases medullary haemorrhages were observed in both suprarenal glands; each of these patients had a sudden collapse just before death, as in a true Waterhouse-Friderichsen syndrome. Seven other cases showed well-marked congestion of the adrenals, but histological examination revealed no significant changes. No other abnormalities of the endocrine system were observed.

Central nervous system. In the fifty-five cases which were examined post-mortem three showed abnormalities in the cerebrospinal fluid before death, in the shape of increased protein, 50 to $80 \mathrm{mg}$. per cent., and increased cells, 13 to 21 lymphocytes per c.mm. In eighteen cases the brain and piaarachnoid were congested, and in thirteen instances small perivascular haemorrhages were observed macroscopically and on histological examination.
Obvious cerebral oedema was noted in three fulminating cases. One case, a male infant aged six months, showed an extensive purulent meningeal exudate most profuse around the base of the brain and along . the Sylvian fissure. Culture of the meningeal exudate yielded a pure growth of Bact. coli neapolitanum. Until a short time before death there was no evidence of meningitis, so this complication was probably a terminal one. Despite the reports by Scandinavian workers, histological examination of the brain tissues failed to show any evidence of perivascular round-cell infiltration.

Middle ear and mastoid. Although the middle ear and mastoid were examined in every case, in only five was there evidence of a purulent exudate. In two of these Bact. coli neapolitanum was isolated, while in the remaining three culture yielded a mixed growth of staphylococci, Str. viridans, and a diphtheroid organism.

\section{Bacteriology}

Despite a great deal of research work the etiology of the disease has not so far been settled. Certain workers have tried to establish a relationship between such organismal causes as Str. faecalis, a specific virus, and certain types of coliform bacilli and the disease. Gale (1944) for instance described strains of Str. faecalis, belonging to Lancefield Group D which could be obtained from cases of infantile gastro-enteritis. This organism produces tyramine, a substance considered to be toxic to young children, and which caused diarrhoea when injected into rats. As regards the virus theory, Barenberg and others (1936) found in some fatal cases mononuclear lung infiltrations which suggested the possibility of a virus infection. Lembcke and others (1943) identified a filterable agent lethal to mice in the faeces of infected babies. Light and Hodes (1943) claimed to have transmitted the disease to calves by the nasal introduction of faecal filtrates and these results were confirmed by Buddingh and Dodd (1944). The virus theory has had some support from the work of Christen and Biering-Soerensen (1946), who found evidence of encephalitis in the shape of round-cell infiltration. On the other hand Pappenheimer and Enders (1947) demonstrated inclusion bodies in the cells of the intestinal mucosa of cases suffering from enteritis. Various strains of coliform organisms have also been suggested as causal agents from time to time. Thus in 1927 Adam concluded that a special type of Bact. coli, characterized biochemically by the fermentation of saccharose and rhamnose was found regularly in the faeces of infants with gastro-enteritis. Less frequently he isolated a different type of coliform which was related to one of Jensen's calf strains. Adam's observations were later confirmed by Cziglány (1941) during an epidemic in Budapest. In 1945 Bray, in this country, published work on a series of fifty-one cases, in over 90 per cent. of which he recovered a serologically homogenous type of Bact. coli neapolitanum 
TABLE 4

THE INCIDENCE OF BACT. COLI TYPE GASTRO-ENTERITIS IN 415 CASES OF INFANTILE DIARRHOEA

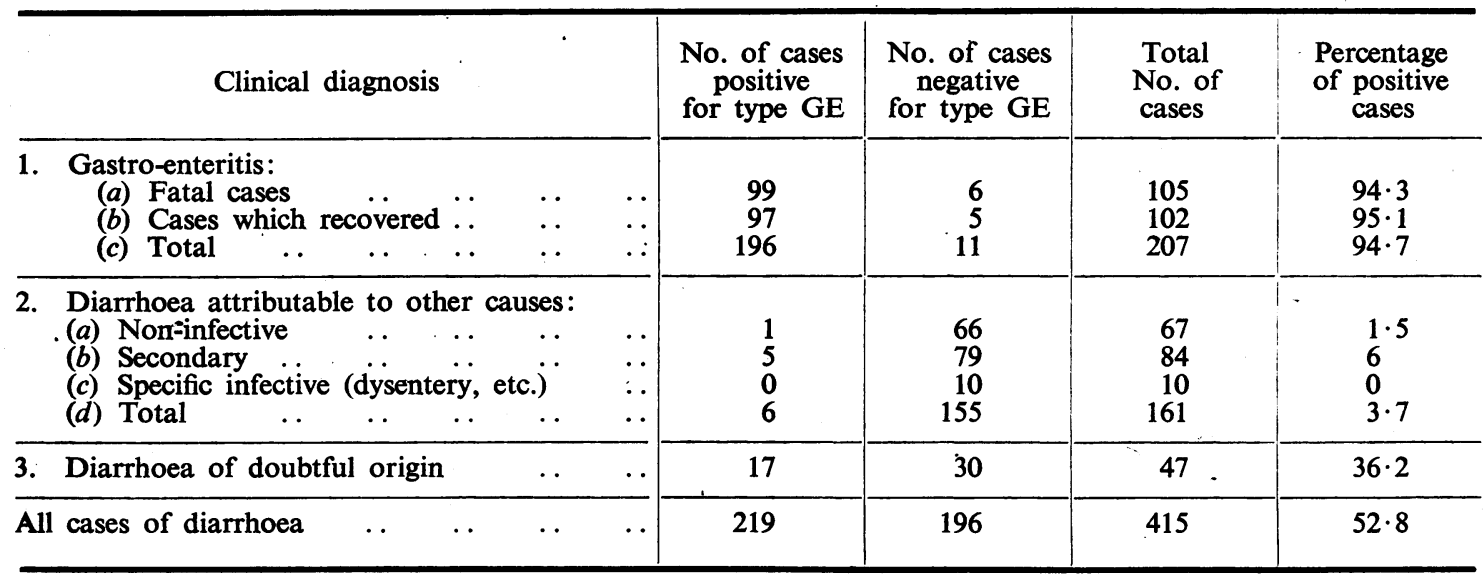

characterized by a peculiar seminal odour when grown on artificial media. A few of the strains, although serologically identical, failed to ferment lactose and should, therefore, be classified as paracolon bacilli. The serology of the coli groups of organisms has been re-investigated in the light of modern knowledge, and this work has been reviewed by Kauffmann (1947) who has also participated largely in its development. The identification of $\mathrm{O}, \mathrm{K}$, and $\mathrm{H}$ antigens has led to the establishment of a diagnostic antigenic scheme by means of which the coli strains can be classified in $O$ groups and types. Not all members of the coli groups are in possession of an $\mathrm{H}$ antigen, and the $\mathbf{K}$ antigens which are associated with the envelope or capsule also play an important part. The $\mathrm{Vi}$ antigens include thermolabile antigens ( $\mathrm{L}$ and $\mathrm{B}$ ) as well as thermostabile antigens (A), while the $L$ and $B$ antigens are mostly envelope antigens corresponding to the $\mathrm{Vi}$ antigen, the $\mathrm{A}$ antigens appear mostly as visible capsules. $O$ inagglutinability at $37^{\circ} \mathrm{C}$. is also of frequent occurrence and is due to the presence of one of the $K$ antigens, particularly the $L$. It may be possible, therefore, that the new knowledge of the serology of the coli group will help to elucidate certain problems connected with the pathogenicity of this organism.

During the course of the epidemic the bacteriological investigation was concentrated on the examination of faeces for (1) Group D streptococci, (2) a possible virus, and (3) special types of Bact. coli. After a considerable amount of work the examination of specimens for Group D streptococci was stopped as this part of the investigation did not seem to be leading to any conclusive result. Similarly after a series of faecal specimens had been filtered and the filtrates injected into the allantoic membranes of developing chick embryos no evidence of the transmission of a virus could be obtained. Work was, therefore, concentrated largely on special types of $\mathrm{B}$. coli.

Preliminary work on the serology of the coliform organisms showed that one particular type was - frequently present, and through the kindness of Dr. R. D. Stuart of Glasgow, cultures and antisera of the organism isolated by Bray were compared with those isolated here, when the various strains were found to be identical. The methods used in the isolation and identification of the organism, the cultural characteristics, and its antigenic properties have already been described (Giles and Sangster, 1948) and it will only be necessary here to give the results of the investigation over the whole year.

A total of 2,150 specimens of faeces from cases and controls were examined between Jan. 1 and Dec. 31, 1947. The results of these tests in 415 cases of infantile diarrhoea are summarized in table 4 . This shows that the B. coli neapolitanum type of organism was present in 94.7 per cent. of cases as opposed to 3.7 per cent. in cases of diarrhoea attributable to other causes. That the presence of this type of organism could not be due simply to cross infection in the wards of the various hospitals was proved by the fact that cases contracting their infection while within their homes showed it as frequently as those contracting their infection in the various institutions. Further, since the first specimens were taken as soon as possible after the patient was admitted there was little chance of their presence being due to cross infection at this stage.

The association of the organism with the disease was, however, even more consistent; thus the faeces of eighty-four out of the total of ninety-seven positive cases which recovered were repeatedly examined at four- to five-day intervals throughout the course of the disease, and in seventy-four cases the organism disappeared from the stools when 
clinical improvement occurred, while in the remaining twelve Bact. coli type neapolitanum was still present when the patients were discharged from hospital. Five of the latter were negative on re-examination as out-patients a month later, and the rest did not return for examination. As a rule the disappearance of this type of Bact. coli coincided fairly closely with clinical improvement, but the patients who passed into a state of marasmus proved exceptions. The onset of marasmus was always insidious, and with these cases, although the organism disappeared from the stool the patient's condition remained precarious. Bacteriological specimens taken at forty autopsies showed the presence of the gastroenteritis type of Bact. coli in the stomach and in the small and large intestines in thirty-five. In five cases which had developed marasmus the organism had disappeared. In ten necropsies the gastro-enteritis type was recovered from the liver, the spleen, the mesenteric glands, and on two occasions from the purulent exudate in the middle ear, and in one instance from the meninges.

In infants suffering from what appeared clinically to be non-infective diarrhoea (dietetic and metabolic disturbances) the organism was isolated from 1.5 per cent. of cases, while in those cases suffering from what appeared to be parenteral infections the incidence was higher, namely 6 per cent. That the organism was also recovered from a substantial proportion (36.2 per cent.) of cases in the group of diarrhoea of doubtful etiology is not surprising, for this group probably included some cases of gastroenteritis not definitely diagnosed as such owing to complicating parenteral infection or lack of clinical data.

In order to assess the significance of the association between Bact.coli type neapolitanum and cases of gastro-enteritis, specimens from an extensive series of 271 infants under the age of two years without diarrhoea, and a group of 450 adults and older children with or without diarrhoea were examined for the presence of the organism. As seen in table 5, Bact. coli type gastro-enteritis was not found in any of the forty healthy breast-fed and only in seven of the 231 bottle-fed infants without diarrhoea, six of these seven control cases being ward contacts of cases of gastro-enteritis. A small number of adults and older children (six in all) showed the presence of the organism in the faeces, one of these being a nurse in one of the wards where an outbreak of the disease had occurred, and another being a patient suffering from mucous colitis. From the above it is clear that the organism under discussion was associated throughout the year very closely with cases of gastro-enteritis, and not with other conditions.

In order to ascertain whether the presence of this coliform produced an antibody-response in patients from whom it was recovered, the sera of forty-one cases were examined for agglutinins to the organism in question. In twenty-one out of the forty-one cases an antibody-titre of from 1 in 40 to 1 in 640 was observed, whereas no significant agglutination occurred with the sera of fifty-three normal infants and in only three out of 127 sera chosen at random from routine specimens. ' $O$ '-suspensions of the organism were, on the whole, more readily agglutinable than living bacterial suspensions.

Attempts to produce gastro-intestinal infections in young animals by means of feeding them on that particular type of Bact. coli were only partially successful. Young mice, rabbits, guinea-pigs, and kittens were used. The only positive results were obtained when three litters of altogether ten newly born guinea-pigs were fed on the organism. Five out of these ten developed diarrhoea, and three subsequently died within forty-eíght hours. Bact. neapolitanum was isolated at autopsy from the blood stream, intestine, liver, spleen, and meninges in all three animals, which also showed fatty changes in the liver and the renal tubules and congestion of the intestinal mucosa and the meninges comparable to those encountered in the human.

However, in the month of November it was noticed that Bact. coli neapolitanum was less frequently associated with cases of gastro-enteritis than had previously been found. Other coliform organisms were obtained from definite cases and anti-sera were prepared for their ' $O$ ' and ' $K$, antigens. By this means another fairly frequently occurring type was identified and has been named for convenience the 'Beta' variety.

TABLE 5

THE INCIDENCE OF BACT. COLI TYPE GASTRO-ENTERITIS IN A GROUP OF 721 CONTROLS.

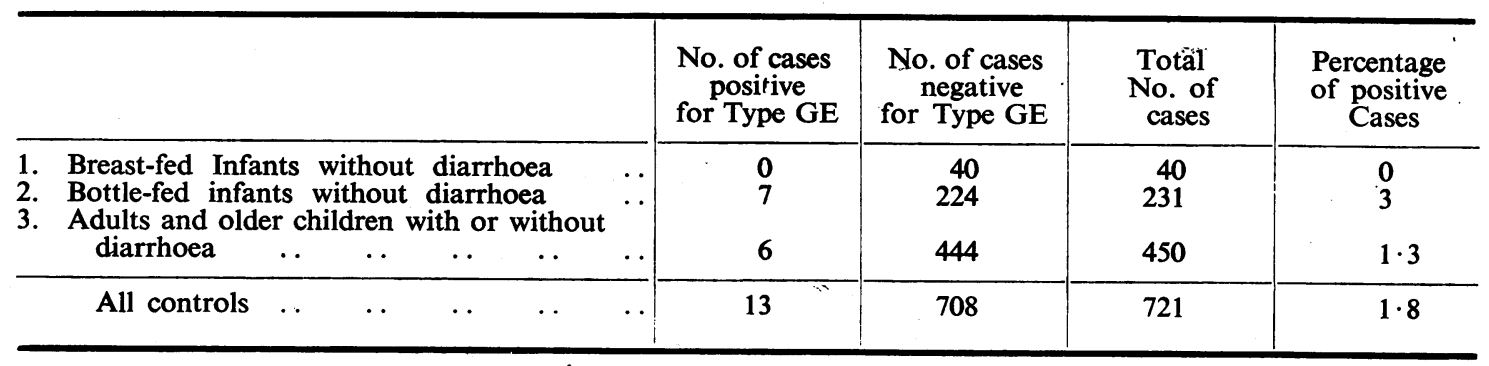


Up until the end of 1947 the beta type has been found in twenty-one out of forty-eight cases of infantile diarrhoea of all types and in three out of fifty-three healthy infants, and in one out of seventyfour adult controls. The forty-eight cases of infantile diarrhoea which were tested for the presence of the organism included nineteen cases of undoubted gastro-enteritis. That the organism has some epidemiological significance can be shown by the fact that two babies from one house were admitted to different hospitals and both showed this Beta type of organism.

The cultural appearance of this organism is in no way different from other coliforms. It is, however, definitely motile, and therefore presumably must have an ' $H$ ' antigen. It ferments lactose, glucose, mannite, saccharose, and dulcitol with the production of acid and gas, but only produces a slight amount of acid and gas in maltose, and does not ferment salicin. Although the organism is definitely motile it has not been found possible so far to produce a ' $\mathrm{H}$ ' antiserum, but ' $\mathrm{K}$ ' and ' $\mathrm{O}$ ' antisera have been obtained from immunized rabbits without difficulty. So far little cross agglutination has been noted between Bact. coli neapolitanum and the Beta type antiserum, and in fact the antiserum prepared from the organism is as specific as the antisera prepared from strains of Bact. coli neapolitanum. Indeed, almost invariably absorption tests have confirmed the results obtained with the slide agglutination tests.

What the exact significance of the presence of these special types of coliform organisms in the faeces has yet to be determined. The most striking fact is that in the case of Bact. coli neapolitanum the organism has been for the most part recovered only from the faeces of infants with diarrhoea presumably resulting from infective gastro-enteritis, and a similar situation is arising in connexion with the Beta strain. Several questions, therefore, arise : (1) Have these organisms any pathogenic significance ? (2) Is their presence in many cases an indication of cross infection? (3) Is it a question of the conditions within the intestine being made suitable for the development and proliferation of these special types of Bact. coli ?

It has been noted repeatedly that the faeces from a case may show negative results for these special types of Bact. coli in the early stage of the disease but later on become positive. Whether this finding is simply a normal occurrence or whether it is due to a cross infection it has not been possible to determine. It has been further noted in hospital that a case may show one type of organism to start with and may then apparently show signs of recovering, and later on a recurrence of the disease may show the second type of organism. It is obvious, however, that much more data will require to be obtained to define the exact relationship of these organisms to the disease and to various epidemiological problems associated with it.

\section{Summary}

1. An outbreak of gastro-enteritis lasting for the greater part of the year 1947 is described.

2. Out of a total of $\mathbf{4 1 5}$ infants who came under observation, 207 were diagnosed as infective gastroenteritis, and of these 105 , or 50.6 per cent., died:

3. The children most affected were bottle-fed babies under seven months, and the peaks of the epidemic occurred in April and July.

4. Institutional outbreaks were a marked feature of the epidemic, and the occurrence of six definite ward outbreaks is recorded. The incidence of these nosocomial cases emphasizes the infective nature of the disease.

5. The clinical findings have been summarized and have not been found to differ to any extent from those which have been described in other epidemics.

6. Post-mortem examination of fifty-five fatal cases showed once again the indefinite pathology associated with this disease. The changes that occurred in the intestines were often minimal, but more frequently the liver was affected to a greater or lesser extent, and the damage varied from slight fatty degeneration to generalized fatty changes and necrosis with little healthy liver parenchyma remaining. There were manifestations of toxic action on the kidneys but no evidence of a virus infection in the central nervous system.

7. Attempts to demonstrate a virus were unsuccessful and no association between Group D streptococci and the disease could be established. Examination of the coliform flora showed that Bact. coli neapolitanum could be recovered from 94.7 per cent. of cases of gastro-enteritis as against an incidence of 3.7 per cent. of cases of diarrhoea attributable to other causes. In infants suffering from what appeared to be dietetic and metabolic disturbances the organism was isolated from 1.5 per cent. of cases, while in diarrhoea associated with parenteral infections the incidence.was slightly higher, namely 6 per cent.

8. In November, 1947, a second type of coliform organism (the Beta variety) became more frequently associated with the cases. It was recovered from twenty-one out of forty-eight cases of infantile diarrhoea, from three out of fifty-three healthy infants, and one out of seventy-four adult control cases. In the faeces of forty breast-fed babies it was not found at all, in 231 bottle-fed infants without diarrhoea it was found seven times, and in specimens from 450 older children and adults it was recovered only six times.

9. The relation of these coliform organisms to the disease has been discussed but no definite conclusion has been vouchsafed. 
REFERENCES

Adam, A. (1927). Jb. Kinderheilk., 116, 8.

Barenberg, L. H., Levy, W., and Grand, M. J. H. (1936) J. Amer. med. Ass., 106, 1256.

Bloch, E. (1941). Brit. med. J., 1, 151.

Bray, J. (1945). J. Path. Bact., 57, 239.

- Brown, G., Crawford, G. J., and Stent, L. (1945). Brit. med. J., 2, 524.

Buddingh, G. J., and Dodd, K. (1944). J. Pediat., 25, 105.

Christensen, E., and Biering-Soerensen, K. (1946). Acta path. microbiol. scand., 23, 395.

Cziglány, F. (1941). Arch. Kinderheilk., 122, 147.

Deeny, J., and O'Brien, D. P. (1946). J. med. Ass. Eire, 19, 178.
Gale, E. F. (1944). . Brit. med. J., 1, 631.

Gairdner, P. (1945). Arch. Dis. Childh., 20, 22.

Giles, C., and Sangster, G. (1948). J. Hyg., Camb., 46, 1 .

Gunn, W. (1945). Practitioner, 154, 348.

Kauffmann, F. (1947). J. Immunol., 57, 71.

Lembcke, P. A., Quinlivan, J. J., and Orchard, N. G. (1943). Amer. J. Publ. Hith., 33, 1263.

Light, J. S., and Hodes, H. L. (1943). Amer. J. Publ. Hlth., 33, 1451.

Ormiston, G. (1941). Lancet, 2, 588.

Pappenheimer, A. M., and Enders, J. F. (1947). J. exp. Med., 85, 417 .

Wright, G. P., and H. P. (1946). J. Hyg., Camb., 44, 480. 